\title{
Correspondence
}

\section{Revisiting the systematic positions of two "Notocupes" species from the Lower Cretaceous of South China (Coleoptera: Polyphaga)}

\author{
YAN-DA LI ${ }^{1,3}$, DI-YING HUANG ${ }^{1,4}$ \& CHEN-YANG CAI ${ }^{1,2,5^{*}}$ \\ ${ }^{1}$ State Key Laboratory of Palaeobiology and Stratigraphy, Nanjing Institute of Geology and Palaeontology, and Center for Excellence \\ in Life and Paleoenvironment, Chinese Academy of Sciences, Nanjing 210008, China \\ ${ }^{2}$ School of Earth Sciences, University of Bristol, Life Sciences Building, Tyndall Avenue, Bristol BS8 1TQ, United Kingdom

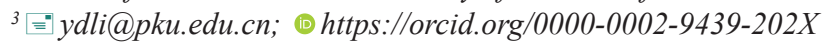

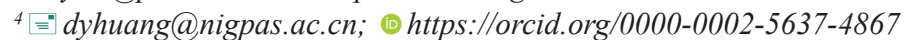 \\ 5 "”cycai@nigpas.ac.cn; @ https://orcid.org/0000-0002-9283-8323 \\ ${ }^{*}$ Corresponding author
}

Artematopodidae is a small family with approximately 70 described extant species (Gimmel \& Bocakova 2015), occupying a basal position in the superfamily Elateroidea (McKenna et al. 2019). The fossil record of artematopodids is sparse, with most species described from the Eocene/Oligocene Baltic amber (Crowson 1973; Hörnschemeyer 1998). Nevertheless, in the past few years, definitive artematopodid fossils have also been reported from the Middle-Late Jurassic Daohugou biota (Cai et al. 2015), the Early Cretaceous Jehol biota (Cai et al. 2020), and the Miocene Mexican amber (Wu et al. 2015). Here we re-examine two fossil specimens from the Lower Cretaceous of South China, which were assigned to the archostematan genus Notocupes Ponomarenko by Lin (1980), i.e., Notocupes undatabdominus and N. ? multituberatus. Our new observation suggests that both specimens do not belong to Notocupes. Notocupes undatabdominus could belong to the polyphagan family Artematopodidae, and Notocupes multituberatus probably belongs to Lasiosynidae.

\section{Material and methods}

The fossils of "Notocupes" undatabdominus (NIGP38559; Figs 1-2) and "N." multituberatus (NIGP38565; Fig. 3) originate from the Shouchang Formation at Xiaqiao Village, Laozhu Town, Lishui City, Zhejiang Province, China (Lin 1980), which has been dated to the Aptian of Early Cretaceous (Li et al. 2018). Both specimens are deposited in the Nanjing Institute of Geology and Palaeontology (NIGP), Chinese Academy of Sciences, Nanjing, China.

Photographs under incident light were taken with a Zeiss Discovery V20 stereo microscope and stacked in Helicon Focus 7.0.2. Scanning electron microscopic (SEM) images were obtained with a Hitachi SU 3500 scanning electron microscope, operating with an accelerating voltage of $15 \mathrm{kV}$ and a pressure of $80 \mathrm{~Pa}$. Images were further processed in Adobe Photoshop CC to enhance contrast.

\section{Results and discussion}

Although "Notocupes" undatabdominus and "N." multituberatus share a somewhat superficially similar body shape with Notocupes, they clearly differ with the latter in many critical characters. In Notocupes, the elytra have relatively large, maculated window punctures, and the elytral epipleura are relatively wide, each with one row of window punctures. By contrast, "N." undatabdominus and "N." multituberatus do not possess such window punctures or wide elytral epipleura (Figs 1, 3A). Additionally, in Notocupes, the abdominal ventrites are overlapping, and there is no mesoventral cavity for reception of the prosternal process, whereas in "N." undatabdominus, the ventrites seem to be connate (Fig. 2D), and there is a distinct mesoventral cavity for reception of the prosternal process (Fig. 2B). Therefore, both fossil species clearly do not belong to Notocupes.

Kirejtshuk (2020) also noticed that these two species are not members of Notocupes, but he didn't transfer them into any other formal group and left them without subordinal and familial attribution. Here we suggest that "N." undatabdominus belongs to the elateroid family Artematopodidae. The prosternum of "N." undatabdominus has a pair of longitudinal carinae (Fig. 2A), which is characteristic of Artematopodidae (Lawrence 2010). Similar well-developed prosternal 
carinae also occur in Throscidae and some members of Elateridae. However, the fossil can be easily separated from these families by its body shape (e.g., prothorax distinctly narrower than elytral width across humeri). Besides, the strongly curved suture between abdominal ventrites 4 and 5 is also indicative of placement in Artematopodidae (Fig. 2D). Currently there are three subfamilies in Artematopodidae (Lawrence 2005). "N." undatabdominus differs from Electribiinae in the absence of the transverse groove on the pronotum, and from Allopogoninae in having distinct paired prosternal carinae. Unfortunately, the specimen of "N." undatabdominus is not well preserved, making it difficult to further compare the fossil with other genera in Artematopodinae.
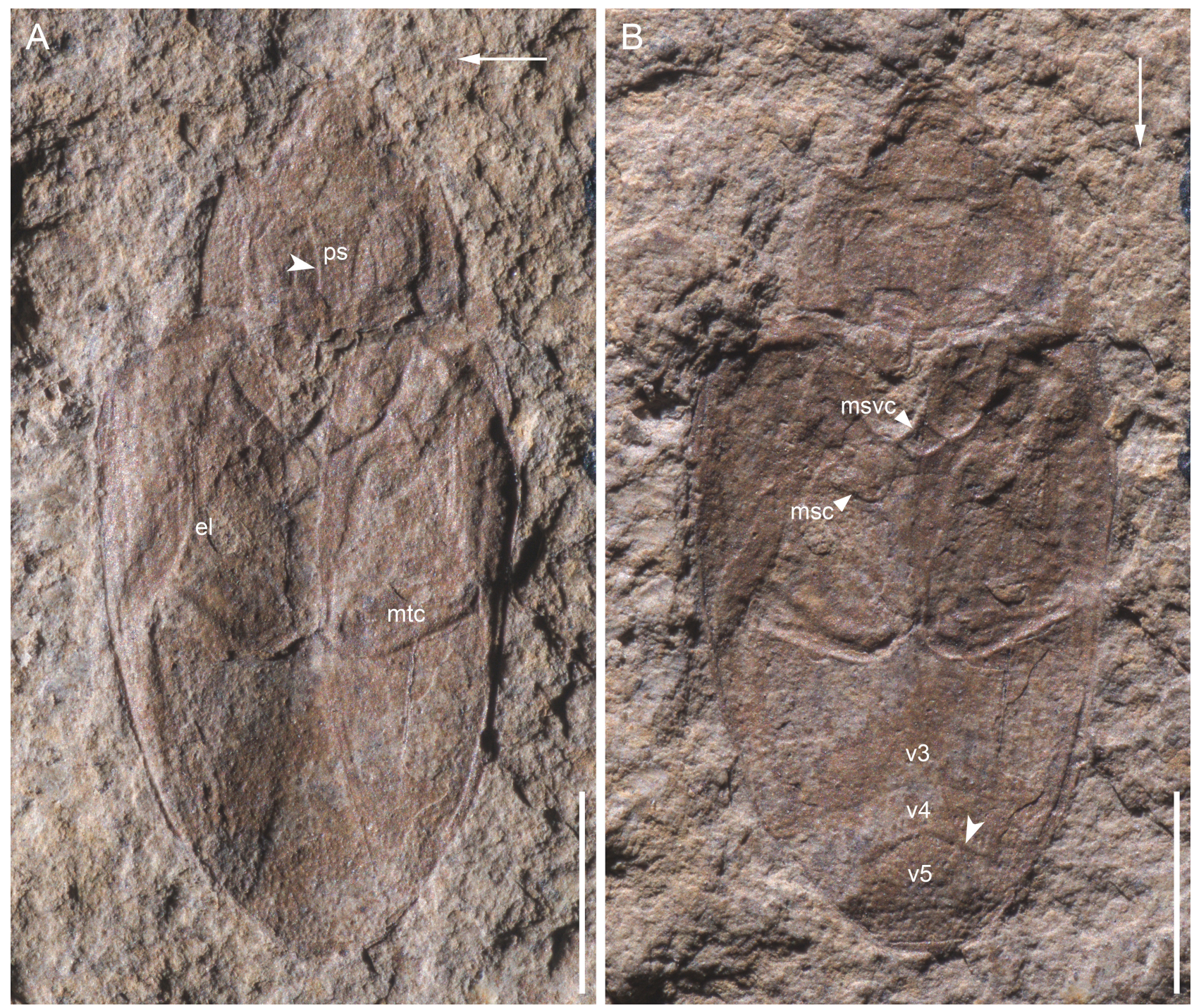

FIGURE 1. General habitus of "Notocupes" undatabdominus, holotype, NIGP38559, under incident light, with prosternal carinae (arrowhead in A) and the curved suture between ventrites 4 and 5 (arrowhead in B) highlighted. Arrows indicate the direction of light. Abbreviations: el, elytron; msc, mesocoxa; msvc, mesoventral cavity; mtc, metacoxa; v3-5, ventrites 3-5. Scale bars: $1.5 \mathrm{~mm}$.

The holotype of "N." multituberatus is even worse preserved than that of "N." undatabdominus. The ventral characters of "N." multituberatus are essentially missing, making it hard to accurately determine its systematic position. Nevertheless, based on the general appearance and elytral morphology, "N." multituberatus could belong to the fossil taxon Lasiosynidae. Each elytron of "N." multituberatus has approximately 11 rows of longitudinal striae (Fig. 3A), with stria 2 (or perhaps stria 3) shortened posteriorly and outer striae not extending to the shoulder region anteriorly (Fig. 3C). These features correspond well to the diagnostic features of Lasiosynidae (Kirejtshuk et al. 2010; Yan et al. 2014). We further tentatively transfer "N." multituberatus into genus Lasiosyne, as Lasiosyne multituberata comb. nov. 

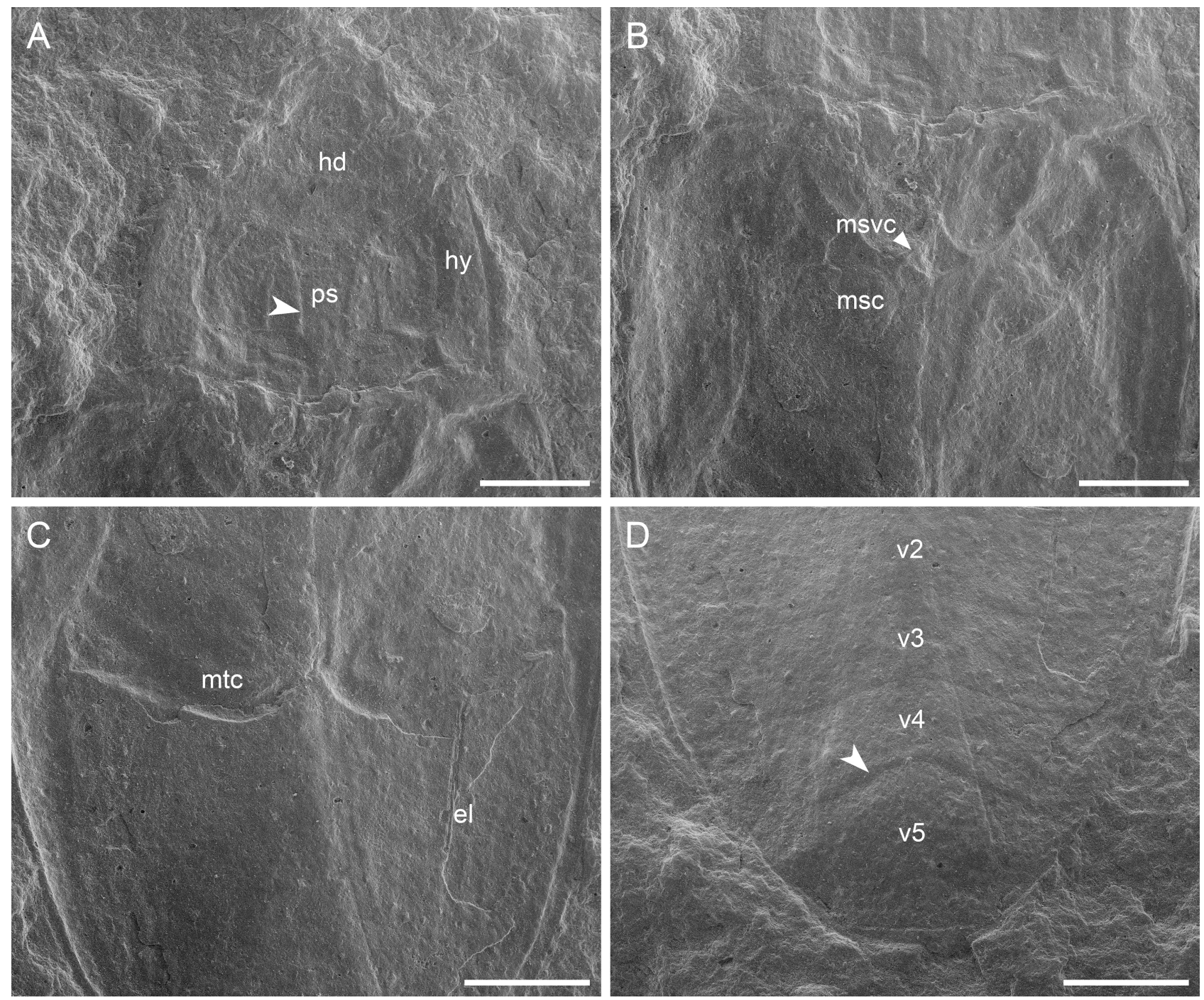

FIGURE 2. Details of “Notocupes” undatabdominus, holotype, NIGP38559, under scanning electron microscopy. A, Head and prothorax, showing the prosternal carinae (arrowhead). B, Mesothorax. C, Metacoxae and abdominal base. D, Abdominal apex, showing the curved suture between ventrites 4 and 5 (arrowhead). Abbreviations: el, elytron; hd, head; hy, hypomeron; msc, mesocoxa; msvc, mesoventral cavity; mtc, metacoxa; v2-5, ventrites $2-5$. Scale bars: $600 \mu \mathrm{m}$.

\section{Acknowledgements}

We are grateful to Thomas Hörnschemeyer, Adam Ślipiński, and one anonymous reviewer for their helpful comments. We thank Chun-Zhao Wang for technical help in SEM imaging, and Dao-Jun Yuan for help in inspecting the specimens deposited at NIGP. Financial support was provided by the Strategic Priority Research Program of the Chinese Academy of Sciences (XDB26000000 and XDB18000000), the National Natural Science Foundation of China (41688103), and the Second Tibetan Plateau Scientific Expedition and Research project (2019QZKK0706). 

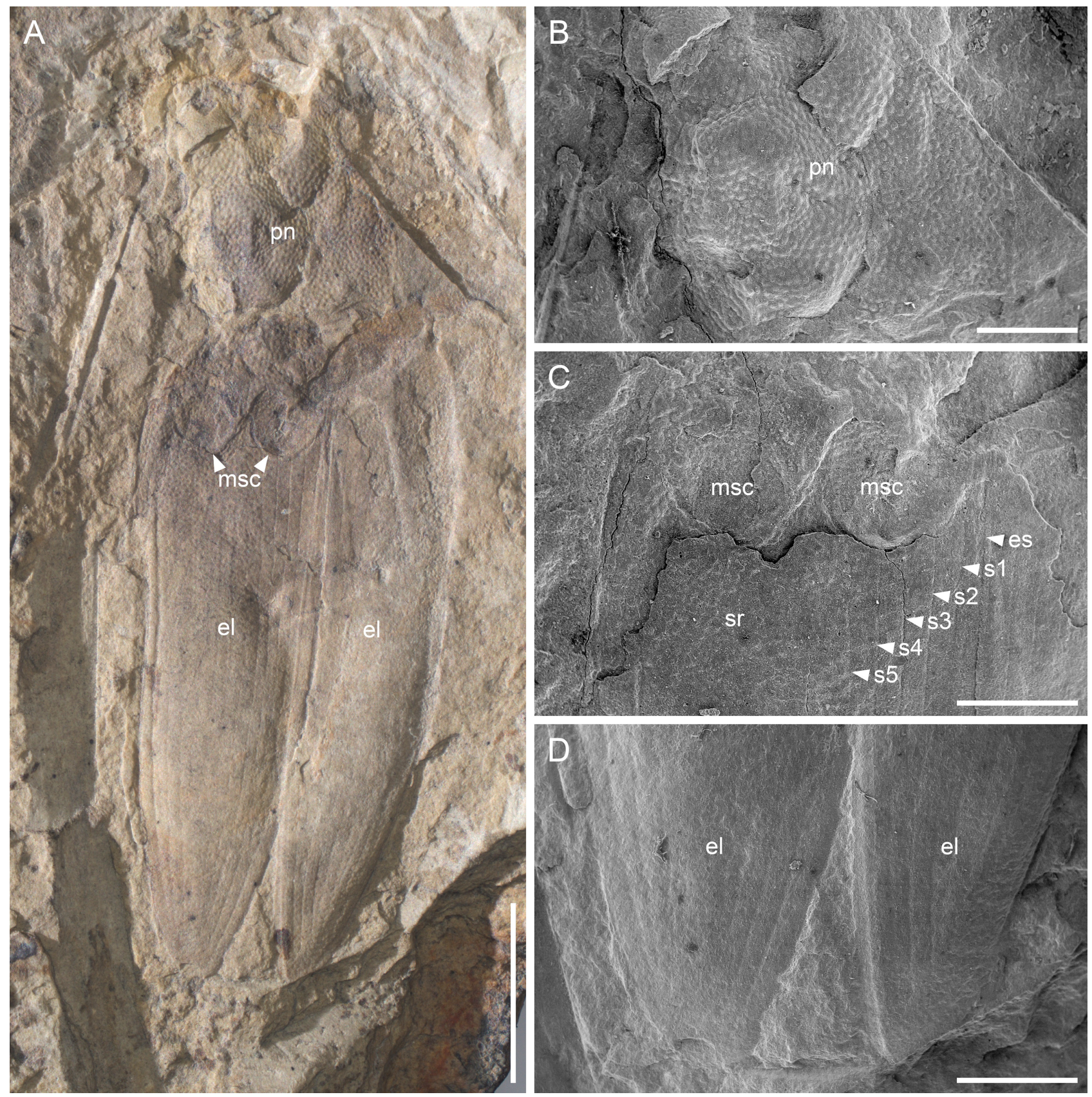

FIGURE 3. Lasiosyne multituberata comb. nov., holotype, NIGP38565, under incident light (A) and scanning electron microscopy (B-D). A, Habitus. B, Prothorax. C, Mesocoxae and elytral base. D, Elytral apex. Abbreviations: el, elytron; es, elytral suture; msc, mesocoxa; pn, pronotum; s1-5, striae 1-5; sr, shoulder region. Scale bars: $3 \mathrm{~mm}$ in A, $1 \mathrm{~mm}$ in B-D.

\section{References}

Cai, C., Lawrence, J.F., Ślipiński, A. \& Huang, D. (2015) Jurassic artematopodid beetles and their implications for the early evolution of Artematopodidae (Coleoptera). Systematic Entomology, 40, 779-788. https://doi.org/10.1111/syen.12131

Cai, C., Fu, Y. \& Huang, D. (2020) A large artematopodid beetle (Coleoptera: Elateroidea: Artematopodidae) from the Early Cretaceous of China and its systematic position. Cretaceous Research, 105, 103986. https://doi.org/10.1016/j.cretres.2018.10.009

Crowson, R.A. (1973) On a new superfamily Artematopoidea of polyphagan beetles, with the definition of two new fossil genera from the Baltic Amber. Journal of Natural History, 7, 225-238. https://doi.org/10.1080/00222937300770181

Hörnschemeyer, T. (1998) New species of Electribius Crowson 1973 (Coleoptera: Artematopodidae) from Baltic amber. Paläontologische Zeitschrift, 72, 299-305. 
https://doi.org/10.1007/BF02988360

Kirejtshuk, A.G. (2020) Taxonomic review of fossil coleopterous families (Insecta, Coleoptera). Suborder Archostemata: superfamilies Coleopseoidea and Cupedoidea. Geosciences, 10, 73.

https://doi.org/10.3390/geosciences10020073

Kirejtshuk, A.G., Chang, H., Ren, D. \& Shih, C.K. (2010) Family Lasiosynidae n. fam., new palaeoendemic Mesozoic family from the infraorder Elateriformia (Coleoptera: Polyphaga). Annales de la Société Entomologique de France, 46, 67-87. https://doi.org/10.1080/00379271.2010.10697640

Lawrence, J.F. (2005) Brevipogon, a new genus of North American Artematopodidae (Coleoptera). The Coleopterists Bulletin, 59, 223-236.

https://doi.org/10.1649/749

Lawrence, J.F. (2010) Artematopodidae Lacordaire, 1857. In: Leschen, R.A.B., Beutel, R.G. \& Lawrence, J.F. (Eds.), Handbook of Zoology, Arthropoda: Insecta, Coleoptera, beetles. Vol. 2. morphology and systematics (Elateroidea, Bostrichiformia, Cucujiformia partim). Walter de Gruyter, Berlin, pp. 42-47.

https://doi.org/10.1515/9783110911213.42

Li, X., Zhang, C., Wang, Y. \& Liu, L. (2018) Geochronostratigraphy and relationship of the Late Mesozoic terrestrial lithostratigraphic units in South China. Acta Geologica Sinica, 92, 1107-1130. [in Chinese]

Lin, Q.-B. (1980) Fossil insects from the Mesozoic of Zhejiang and Anhui Provinces. In: Nanjing Institute of Geology and Palaeonotology (Ed.), Division and Correlation of the Mesozoic Volcano-Sedimentary Strata in Zhejiang and Anhui Provinces. Science Press, Beijing, pp. 114-123. [in Chinese]

McKenna, D.D., Shin, S., Ahrens, D., Balke, M., Beza-Beza, C., Clarke, D.J., Donath, A., Escalona, H.E., Friedrich, F., Letsch, H., Liu, S., Maddison, D., Mayer, C., Misof, B., Murin, P.J., Niehuis, O., Peters, R.S., Podsiadlowski, L., Pohl, H., Scully, E.D., Yan, E.V., Zhou, X., Ślipiński, A. \& Beutel, R.G. (2019) The evolution and genomic basis of beetle diversity. Proceedings of the National Academy of Sciences, USA, 116, 24729-24737. https://doi.org/10.1073/pnas.1909655116

Wu, H., Coty, D. \& Ding, M. (2015) First artematopodid beetle in Mexican amber and its biogeographic implications (Coleoptera, Artematopodidae). Alcheringa, 39, 508-513. https://doi.org/10.1080/03115518.2015.1041306

Yan, E.V., Wang, B. \& Zhang, H. (2014) Two new genera of Lasiosynidae (Insecta, Coleoptera) from the Lower Cretaceous of Russia and Mongolia, and principal trends of the morphological evolution of the family. Paleontological Journal, 48, 500-511.

https://doi.org/10.1134/S0031030114050128 